ISSN 1991-8631

Original Paper

http://indexmedicus.afro.who.int

\title{
Correlation among trace metals in Tilapia (Oreochromis niloticus), sediment and water samples of lakes Awassa and Ziway, Ethiopia
}

\author{
Kebede NIGUSSIE ${ }^{1,2}$, Bhagwan Singh CHANDRAVANSHI ${ }^{1 *}$ and \\ Taddese WONDIMU ${ }^{1}$ \\ ${ }^{1}$ Department of Chemistry, Addis Ababa University, P. O. Box 1176, Addis Ababa, Ethiopia. \\ ${ }^{2}$ Permanent Address: Department of Chemistry, Mekelle University, P. O. Box 231, Mekelle, Ethiopia. \\ *Corresponding author; E-mail: bhagnan@chem.aau.edu.et,bscv2006@yahoo.com; Tel: 251-11-1239466
}

\begin{abstract}
Samples of fish organs, sediment and water were collected from five sampling sites of Lakes Awassa and Ziway. A procedure consuming $13 \mathrm{~mL}$ mixture of $\mathrm{HNO}_{3}-\mathrm{HClO}_{4}-\mathrm{H}_{2} \mathrm{O}_{2}$ for intestine and sediment or 5.0 $\mathrm{mL}$ mixture of $\mathrm{HNO}_{3}-\mathrm{H}_{2} \mathrm{O}_{2}$ for scale, spleen and bile for digestion of freeze-dried fish organs (except bile) and sediment was developed. Concentrations of eight metals were determined using flame atomic absorption spectrophotometer. Concentrations of metals in bile, intestine, scale, spleen and sediment varied (mg/kg): Cd 0.83-13.41, 2.67-5.01, 4.46-13.24, 2.58-6.66, 3.19-10.51, respectively; Cr 0.79-4.27, 1.13-5.09, 2.13-5.74, 0.47-1.36, 4.14-8.66, respectively; Co 0.51-1.19, 0.95-6.10, 5.33-10.96, 10.53-13.20, 9.42-37.72, respectively; $\mathrm{Cu}$ 4.76-12.71, 7.81-15.33, 6.04-24.49, 2.91-16.48, 26.91-78.49, respectively; $\mathrm{Pb}$ 5.73-14.86, 6.24-12.12, 37.29-56.03, 1.46-3.88, 8.49-20.18, respectively; Mn 0.82-5.78, 6.87-58.94, 36.14-135, 0.54-2.84, 106-198, respectively; $\mathrm{Ni} 4.17-5.81,3.04-6.69,42.33-46.41,0.77-2.78,8.09-24.00$, respectively; Zn 18.42-55.79, 22.48$32.48,68.68-91.27,4.81-38.78,108-174$, respectively. Most of the elements in water samples occurred below detection limit. The pattern for concentrations of trace metals followed: sediment $>$ scale $>$ intestine $>$ bile $>$ spleen > water. Using a ternary plot, positive correlation was observed for the specific fish organ with the sediment and water samples. There was no significant difference between the two lakes in accumulating trace metals however Lake Awassa had higher concentration.

(C) 2010 International Formulae Group. All rights reserved.
\end{abstract}

Keywords: Fish, Lake Pollution, Toxic Elements, Bioaccumulation

\section{INTRODUCTION}

With changing environmental conditions and increasing anthropogenic influences, the nature of water bodies that serve as a habitat for aquatic life will change. Studies on the level of trace elements in organisms inhabiting in lakes and other water bodies provide information on the status of the aquatic environment and the biota residing in them. Many studies of metals in fish of fresh waters, wetlands and seas indicate an accumulation of trace elements and raise serious environmental concern. A number of analyses of elements in different organs and tissues of fishes have been reported worldwide (Turkmen and Ciminli, 2007; Olowu et al., 2010; Yilmaz et al., 2010). The high levels of contaminants seen in aquatic biota are known to indicate health risks to both the aquatic organisms and human beings. 
Among the myriad of organic and inorganic substances released into aquatic ecosystems, heavy metals have received considerable attention due to their toxicity and potential bioaccumulation in many aquatic species. The presence of heavy metals in aquatic ecosystem is the result of two main sources of contamination: natural processes or natural occurring deposits and anthropogenic activities (Pourang et al., 2005). Sediments are important sinks for various pollutants like pesticides and heavy metals and also play a significant role in the remobilization of contaminants in aquatic systems under favorable conditions and in interactions between water and sediment. Fish samples can be considered as one of the most significant indicators in freshwater systems for the estimation of metal pollution level (Rashed, 2001; Öztürk et al., 2009).

The source of major pollutants affecting Ethiopian lakes and rivers are not known definitely but appear to include sediment transport and siltation, industrial discharge from a few factories and mining operations and runoff from agricultural fields, and domestic sewage. It has been reported that effluents from the tannery at Koka Reservoir and textile industry in Awassa and Arbaminch had affected the fish resources. Although, Ethiopia does not have industries that flourish in the developed countries and pollutants are not produced in large quantities, rivers such as Tikur Wuha in Awassa and Meki River in Meki towns that flow into Lakes Awassa and Ziway, respectively, carry contaminated discharges from factories and domestic sources (Gebremariam and Desta, 2002).

Moreover, natural factors such as soil erosion, sediment loading, deposition of animal and plant debris, and solution of minerals in the basin obviously bear responsibility for the change in chemical composition of the aquatic system. For instance, effect of erosion, which ends up in lakes increases the nutrient load which leads to killing of fishes in Lakes Chamo and Abijata (Ethiopia) as a result of decreasing oxygen concentration and algal blooms (Breuil, 1995). A number of lakes that have scientific and economic importance are found in Ethiopia. Among these are Lakes Awassa and Ziway, which receive a great deal of research interest because of inhabiting indigenous population of edible fish, supporting variety of aquatic life, high productivity in fishery, and raising environmental concerns. Due to the growth of anthropogenic effects, mainly in agricultural development (application of fertilizers and pesticides), industrialization and population growth, the quality of the lake water and also the safety of aquatic biota may be threatened.

Oreochromis niloticus (Tilapia) in some large lakes is notable and this species constitutes the largest component of the commercial inland fish catch in Ethiopia, species of the family Cyprinidae are the most diverse group countrywide. The predominance of this group in East African waters is never in dispute and might have been favored by the generally high altitude habitats of the region (Getahun and Stiassny, 1998). Tilapia constitutes about 50 to $60 \%$ by weight of the fish population of Lake Awassa and about 94\% of Lake Ziway (Alemu, 2003). In many cases, Tilapia was used as a bioassay organism in toxicological studies in which it was substantiated with the highest sensitivity to toxic effect (Rashed, 2001). Lakes Awassa and Ziway are northern lakes of the Ethiopian Rift Valley lakes in which both are rich in fish fauna mainly the highland East African forms (includes the genera Oreochromis, Barbus, Clarias, Garra and Varicorhinus). In some large lakes from the native Cichlid, Oreochromis niloticus is the notable species and the largest component of the commercial inland fish catch in the country. Both of the lakes are in the neighborhood of the fastgrowing cities, Awassa and Ziway. Due to the increase in population and industrialization of the cities, domestic and industrial effluents may find their ways into the lakes (Getahun and Stiassny, 1998).

The purpose of this study was to determine the concentration and distribution of selected trace elements in fish organ (bile, intestine, scale and spleen), water and bed 
sediment in Lakes Awassa and Ziway with the view to evaluating levels of aquatic pollution and establishing relations among trace element concentrations in fish organs and, water and bed sediment and basin wide land use, geology and mining activities. The study was also aimed at identifying potential sources of trace elements contaminating the lakes and inhabiting biota.

\section{MATERIALS AND METHODS Study area}

Lake Awassa is located $6^{\circ} 33^{\prime}-7^{\circ} 33^{\prime} \mathrm{N}$ and $30^{\circ} 22^{\prime}-38^{\circ} 29^{\prime} \mathrm{E}$ an altitude of $1680 \mathrm{~m}$. The Awassa basin is in the middle of the Ethiopian Rift Valley, between the AbijataShalla basin to the north and that of Lakes Abaya and Chamo to the south. The Shallo swamp drains into Lake Awassa through a small river called Tiqur Wuha. There are no outlets from the lake, but water may seep away through the underlying volcanic ash and pumice. The surface area ranges between 8,500 and 9,000 ha and the maximum depth is about $18-22 \mathrm{~m}$. The threats for the lake are Awassa Textile Factory, the amount of solid and liquid wastes generated by different sectors, various agrochemicals in small- and large-scale farming (like center for preparation and expansion of selected seeds) and also sewer lines (which end up in the lake). The most important commercial species is Oreochromis niloticus, but there are also good populations of catfish and Barbus (Breuil, 1995). Lake Ziway is located $7^{\circ} 52^{\prime}$ $8^{\circ} 40^{\prime} \mathrm{N}$ and $38^{\circ} 40^{\prime}-38^{\circ} 56^{\prime} \mathrm{E}$. Its altitude is $1636 \mathrm{~m}$ and the largest and shallowest lake in the Central Main Ethiopian Rift Valley. It has an area of $440 \mathrm{~km}^{2}$; a maximum depth of 8.9 $\mathrm{m}$ and a mean depth of $2.5 \mathrm{~m}$. Lake Ziway is fed by the two major rivers, Meki and Katar, which drain from Northwestern and Southwestern plateaus, respectively. It flows into Lake Abijata via Bulbula River and is being used for irrigation purposes (Ataro et al., 2003; Kebede and Wondimu, 2004). Selection of sampling sites in each lake was based on the availability of the fish species of interest and proximity to anthropogenic influence. Considering sampling sites in Lake Awassa, Tikur Wuha and Shallo were chosen as sites prone to agricultural and industrial contamination, while Minch was considered as site away from point source. In case of Lake Ziway, Bochesa and Deset were selected due to the availability of the selected fish species. Moreover, Bochesa was found at extreme end of Lake Ziway. Therefore, analyzing fish, sediment and water from these sites could indicate any associated pollution in the area.

\section{Sample collection Fish sampling}

All glassware and apparatus used in analytical work were soaked in detergents for $24 \mathrm{~h}$, rinsed with water, soaked in $10 \%$ nitric acid (Spectrosol®, England) for $24 \mathrm{~h}$, rinsed with distilled deionized water and then kept in an oven at $110{ }^{\circ} \mathrm{C}$ until needed (Mwashote, 2003). The selected fish species, Tilapia, $O$. niloticus, were randomly collected (five from each site) in two campaigns with the help of local fishermen within the sampling stations. The fish samples were washed with lake water and placed on a plastic sheet. First the scales of the fish were removed with plastic knife and placed in a labeled plastic bag. After dissecting the fish, selected body parts (bile, spleen and intestine) were taken cautiously and separately placed in labeled plastic bags. The intestine was squeezed before placing in the bags to remove its content and dissected longitudinally. The plastic bags were closed with masking tape and frozen in icebox and transported to the laboratory for further treatment. They were stored in a laboratory refrigerator at $-20{ }^{\circ} \mathrm{C}$ until analysis. The selected parts (except bile) were placed in freeze drier (FREEZE DRY-3, LABCONCO, Kenucky, USA) until a constant mass was obtained. To get a representative sample, the dried samples were thoroughly homogenized and placed in a wide neck reagent glass bottles. The bile sample was sucked with a syringe fitted with a plastic tip and was placed in glass bottles. At all sites, bile, intestine, 
scale and spleen samples were removed from different individuals of the same species and combined for a single composite sample.

\section{Sediment sampling}

Sediment samples were collected from a depth of $20-30 \mathrm{~cm}$ from the same locality at which the fish samples were collected. The composite samples were then placed in a 500 $\mathrm{mL}$ polyethylene bottles. The samples were kept in icebox till transported to the laboratory. They were kept in deep-freezer until drying. In the laboratory, the sediments were freeze-dried. The composited (homogenized) dried sample was sieved with a 1-mm sieve and placed in reagent bottles (Mwashote, 2003).

\section{Water sampling}

1-L polyethylene bottles were used for collecting water samples. The bottles were cleaned with detergents and rinsed with deionized water. During the sampling period the bottles were rinsed with the lake water three times and then used for collecting the samples. Water samples were collected from a depth of $20-30 \mathrm{~cm}$ from the same locality and duration of time at which fish and sediment samples were collected. The collected samples were placed in icebox.

\section{Sample preparation}

Digestion of bile, scale and spleen samples

An aliquot of samples $(1.0000 \mathrm{~g}$ scale $/ 0.5000 \mathrm{~g}$ spleen $/ 0.50 \mathrm{~mL}$ bile) was measured and placed in $150-\mathrm{mL}$ round bottom flask. $3.0 \mathrm{~mL}$ of conc. $\mathrm{HNO}_{3}$ (Spectrosol ${ }^{\circledR}$, England) was added to it and kept for $30 \mathrm{~min}$ for the completion of the action of the acid. After fitting a condenser to it and placing on a hot plate, it was refluxed for $30 \mathrm{~min}$. After cooling for $5 \mathrm{~min}, 2.0 \mathrm{~mL}$ of $\mathrm{H}_{2} \mathrm{O}_{2}$ (Spectrosol $囚, \mathrm{BDH}$, England) was added and the mixture was refluxed for $15 \mathrm{~min}$. Then the condenser was removed and direct heating was continued until about $1 \mathrm{~mL}$ solution remained in the flask. The cooled digest was transferred to $25-\mathrm{mL}$ volumetric flask using a dropper and diluted to the mark with distilled, deionized water containing $1.5 \mathrm{~mL}$ conc. $\mathrm{HNO}_{3} / \mathrm{L}$. It was kept in the refrigerator until analysis. Samples were digested in triplicate and blank solutions were prepared in the same way as the sample.

\section{Digestion of intestine and sediment samples}

A $1.0000 \mathrm{~g}$ intestine/sediment portion was placed into $150-\mathrm{mL}$ round bottom flask. To this, $6 \mathrm{~mL}$ of conc. $\mathrm{HNO}_{3}$ was added and the mixture was stood for $30 \mathrm{~min}$. After fitting a condenser and placing on a hot plate it was refluxed for $45 \mathrm{~min}$. After cooling for $5 \mathrm{~min} 4$ $\mathrm{ml}$ of conc. $\mathrm{HClO}_{4}$ (Aldrich, A.C.S. Reagent, Germany) was added and refluxing was continued for $45 \mathrm{~min}$. After cooling for $5 \mathrm{~min}$, $3 \mathrm{~mL} \mathrm{H}_{2} \mathrm{O}_{2}$ was added and the mixture was refluxed for $15 \mathrm{~min}$. After removing the condenser, direct heating was continued until white fume or semi-dryness was observed. The cooled intestine digest was transferred to 25 -mL volumetric flask, diluted to the mark. The digest of the sediment sample was filtered through D4 sintered glass filter unit (Duran 50, Schott Mainz, Germany) and the filtrate was diluted to $100 \mathrm{~mL}$ with the acidified distilled, deionized water.

\section{Preparation of water samples}

In the laboratory, the water sample was centrifuged and about $500 \mathrm{~mL}$ of water was filtered through $0.45-\mu \mathrm{m}$ micropore filters (Mwashote, 2003). The filtrate was acidified with $1.00 \mathrm{~mL}$ conc. $\mathrm{HNO}_{3}$ and kept in the refrigerator at $4{ }^{\circ} \mathrm{C}$ until analysis.

\section{Determination of trace elements}

A series of working standard solutions of metals were prepared by appropriate dilution of the metal stock solutions (PuroGraphic $^{\text {tm }}$ calibration standards, Buck Scientific, USA.) with distilled deionized water containing $1.5 \% \quad \mathrm{HNO}_{3}$. Then the calibration graph was constructed for each element using the prepared standard solutions. Trace elements in the prepared samples of fish organs, sediment and water were determined with the Buck Scientific 210VGP atomic absorption spectrophotometer (East Norwalk, USA). 


\section{Method validation}

The performance of the method was validated by analyzing samples spiked with known standard solutions subsequently subjected to appropriate treatment (e.g., digestion and filtration). The procedure was as follows: $0.20 \mathrm{~mL}, 1.50 \mathrm{~mL}$ or $2.50 \mathrm{~mL}$ of a $10.00 \mathrm{ppm}$-metal solutions were added to 1.00 $\mathrm{g}$ intestine, $0.50 \mathrm{~g}$ of scale, and $1.00 \mathrm{~g}$ of sediment sample, respectively. Then, spiked samples were digested in triplicate applying the developed digestion method for organs and sediment. Trace elements in these diluted digests were determined with flame atomic absorption spectrometer.

\section{Statistical analysis}

Statistical analysis of data was carried out with the SPSS v16.0 for Windows statistical program. Moreover Microsoft Excel 2007, Microcal Origin 8.0, ternary plot and Pearson's correlation matrix at $95 \%$ confidence interval were used.

\section{RESULTS}

\section{Dry mass determination}

The range for percentage moisture content was $78.12 \%$ to $83.46 \%$ for intestine, $38.81 \%$ to $52.07 \%$ for scale, and $75.06 \%$ to $80.86 \%$ for spleen.

The optimized procedures for the different samples are different depending on their nature/matrix. Some of the criteria for selecting digestion procedure were ease of digestion, reduced reagent consumption, reduced digestion time and quantitative recovery of analytes. For bile, scale and spleen sample the digestion was performed with $3.0 \mathrm{~mL} \mathrm{HNO}_{3}$ and $2.0 \mathrm{~mL}$ of $\mathrm{H}_{2} \mathrm{O}_{2}$ in that order, taking digestion time of 1.5 hours. It can be generalized that these organs contain clean and easily oxidizable substances so that nitrate solutions of the metals are obtained. Sediment and intestine contain silica and are difficult-to-oxidize substances. Consequently, digestion of these samples was achieved using $6.0 \mathrm{~mL}$ of $\mathrm{HNO}_{3}, 4.0 \mathrm{~mL} \mathrm{HClO}_{4}$ and $2.0 \mathrm{~mL}$ of $\mathrm{H}_{2} \mathrm{O}_{2}$ in that order by heating for 2.0 hours. The detection limits of each element were calculated as three times the standard deviation of the blank $\left(3 \sigma_{\text {blank }}, \mathrm{n}=18\right)$ prepared under optimal digestion conditions. Table 1 summarizes detection limits for the elements determined.

\section{Recovery of metals}

The performance of the optimized methods was evaluated employing spiking experiments in which the concentration of the analyte is already known. The recoveries of metals in the spiked samples were obtained between $87.7 \%$ to $107.5 \%$ (intestine), $85.8 \%$ to $101.4 \%$ (scale) and $85.8 \%$ to $107.0 \%$ (sediment). The results are displayed in Table 2 , which indicate that good recoveries were obtained for the trace metals. Thus, the developed digestion procedures were considered reliable and were applied for the determination of trace metals in digests of intestine, scale, sediment and bile.

\section{Distribution of the selected elements in fish}

The concentrations of the selected trace elements in the different organs of the fish, water and sediment samples are given in Tables 3 and 4. The concentrations of the eight metals in the bile, intestine, scale, spleen and sediment varied $(\mathrm{mg} / \mathrm{kg})$ : Cd 0.83-13.41, 2.67-5.01, 4.46-13.24, 2.58-6.66, 3.19-10.51, respectively; $\mathrm{Cr} 0.79-4.27,1.13-5.09,2.13-$ 5.74, 0.47-1.36, 4.14-8.66, respectively; Co 0.51-1.19, 0.95-6.10, 5.33-10.96, 10.53-13.20, 9.42-37.72, respectively; $\mathrm{Cu} 4.76-12.71,7.81-$ 15.33, 6.04-24.49, 2.91-16.48, 26.91-78.49, respectively; $\mathrm{Pb}$ 5.73-14.86, 6.24-12.12, 37.29-56.03, 1.46-3.88, 8.49-20.18, respectively; $\mathrm{Mn} \quad 0.82-5.78, \quad 6.87-58.94$, 36.14-135, 0.54-2.84, 106-198, respectively; $\mathrm{Ni}$ 4.17-5.81, 3.04-6.69, 42.33-46.41, 0.772.78 , 8.09-24.00, respectively; $\mathrm{Zn} 18.42-$ 55.79, 22.48-32.48, 68.68-91.27, 4.81-38.78, 108-174, respectively. Most of the elements in water samples occurred below the detection limit of instrument. 
Table 1: Instrument operating parameters and detection limits for trace elements.

\begin{tabular}{lcccc}
\hline \multirow{2}{*}{ Element } & \multicolumn{4}{c}{ Detection limits (mg/kg) in sample of } \\
\cline { 2 - 5 } & Sediment & Intestine & Bile/Scale & Water* \\
\hline $\mathrm{Cd}$ & 0.01 & 0.08 & 0.04 & 0.005 \\
$\mathrm{Cr}$ & 0.06 & 0.09 & 0.06 & 0.05 \\
$\mathrm{Co}$ & 0.08 & 0.09 & 0.06 & 0.05 \\
$\mathrm{Cu}$ & 0.09 & 0.03 & 0.03 & 0.02 \\
$\mathrm{~Pb}$ & 0.11 & 0.12 & 0.11 & 0.1 \\
$\mathrm{Mn}$ & 0.02 & 0.04 & 0.01 & 0.01 \\
$\mathrm{Ni}$ & 0.08 & 0.04 & 0.04 & 0.04 \\
$\mathrm{Zn}$ & 0.10 & 0.05 & 0.02 & 0.005 \\
\hline \multicolumn{4}{l}{ * The detection limit for water is considered as the instrument detection limit. }
\end{tabular}

Table 2: Recovery of metals determined in spiked and digested samples of fish organs and sediment.

\begin{tabular}{|c|c|c|c|c|}
\hline Metal & $\begin{array}{l}\text { Sample } \\
\text { type }\end{array}$ & $\begin{array}{c}\text { Amount added, } \\
\text { mg/L }\end{array}$ & $\begin{array}{c}\text { Amount found, } \\
\mathrm{mg} / \mathrm{L}\end{array}$ & \% Recovery \\
\hline \multirow{3}{*}{ Cadmium } & Intestine & 0.200 & $0.207 \pm 0.001$ & $103.5 \pm 0.1$ \\
\hline & Scale & 0.600 & $0.608 \pm 0.011$ & $101.4 \pm 1.1$ \\
\hline & Sediment & 1.000 & $1.057 \pm 0.003$ & $105.7 \pm 0.3$ \\
\hline \multirow{3}{*}{ Chromium } & Intestine & 0.200 & $0.185 \pm 0.004$ & $92.4 \pm 2.0$ \\
\hline & Scale & 0.600 & $0.530 \pm 0.006$ & $88.3 \pm 0.6$ \\
\hline & Sediment & 1.000 & $0.879 \pm 0.032$ & $87.9 \pm 3.2$ \\
\hline \multirow{3}{*}{ Cobalt } & Intestine & 0.200 & $0.194 \pm 0.005$ & $97.2 \pm 0.5$ \\
\hline & Scale & 0.600 & $0.553 \pm 0.047$ & $92.2 \pm 4.7$ \\
\hline & Sediment & 1.000 & $0.916 \pm 0.026$ & $91.6 \pm 2.6$ \\
\hline \multirow{3}{*}{ Copper } & Intestine & 0.200 & $0.182 \pm 0.006$ & $91.1 \pm 0.6$ \\
\hline & Scale & 0.600 & $0.531 \pm 0.026$ & $88.5 \pm 2.6$ \\
\hline & Sediment & 1.000 & $0.855 \pm 0.036$ & $85.5 \pm 3.6$ \\
\hline \multirow{3}{*}{ Lead } & Intestine & 0.200 & $0.175 \pm 0.007$ & $87.7 \pm 0.7$ \\
\hline & Scale & 0.600 & $0.548 \pm 0.062$ & $91.3 \pm 6.2$ \\
\hline & Sediment & 1.000 & $0.885 \pm 0.026$ & $88.5 \pm 2.6$ \\
\hline \multirow{3}{*}{ Manganese } & Intestine & 0.200 & $0.183 \pm 0.001$ & $91.7 \pm 0.1$ \\
\hline & Scale & 0.600 & $0.515 \pm 0.017$ & $85.8 \pm 1.7$ \\
\hline & Sediment & 1.000 & $0.952 \pm 0.009$ & $95.2 \pm 0.9$ \\
\hline \multirow{3}{*}{ Nickel } & Intestine & 0.200 & $0.215 \pm 0.005$ & $107.5 \pm 0.5$ \\
\hline & Scale & 0.600 & $0.578 \pm 0.006$ & $96.3 \pm 0.6$ \\
\hline & Sediment & 1.000 & $1.070 \pm 0.005$ & $107.0 \pm 0.5$ \\
\hline \multirow{3}{*}{ Zinc } & Intestine & 0.200 & $0.186 \pm 0.008$ & $91.5 \pm 0.8$ \\
\hline & Scale & 0.600 & $0.548 \pm 0.007$ & $91.3 \pm 0.7$ \\
\hline & Sediment & 1.000 & $0.993 \pm 0.024$ & $101.7 \pm 2.4$ \\
\hline
\end{tabular}


Table 3: Trace element concentrations in organs of $O$. niloticus, sediment and water samples from Lakes Awassa and Ziway.

\begin{tabular}{|c|c|c|c|c|c|c|}
\hline \multirow[t]{2}{*}{ Type } & \multirow{2}{*}{$\begin{array}{l}\text { Name of } \\
\text { Lake }\end{array}$} & \multirow{2}{*}{$\begin{array}{l}\text { Sampling } \\
\text { Site }\end{array}$} & \multicolumn{4}{|c|}{ Concentration (mg element/kg)*, dry weight } \\
\hline & & & Cadmium & Chromium & Cobalt & Copper \\
\hline \multirow{5}{*}{ Bile } & \multirow{3}{*}{ Awassa } & Deset & $13.41 \pm 0.04$ & $0.79 \pm 0.07$ & $0.53 \pm 0.15$ & $10.53 \pm 0.10$ \\
\hline & & Minch & $6.41 \pm 0.06$ & $3.23 \pm 0.06$ & $0.67 \pm 0.34$ & $4.76 \pm 0.07$ \\
\hline & & T. Wuha & $7.71 \pm 0.04$ & $4.27 \pm 0.31$ & $1.19 \pm 0.15$ & $12.71 \pm 0.13$ \\
\hline & \multirow{2}{*}{ Ziway } & Bochesa & $14.63 \pm 0.11$ & $1.94 \pm 0.07$ & $0.51 \pm 0.29$ & $7.52 \pm 0.15$ \\
\hline & & Shallo & $0.83 \pm 0.02$ & $2.21 \pm 0.07$ & $0.56 \pm 0.08$ & $11.41 \pm 0.08$ \\
\hline \multirow{5}{*}{ Intestine } & \multirow{3}{*}{ Awassa } & Deset & $2.73 \pm 0.02$ & $3.80 \pm 0.02$ & $1.12 \pm 0.09$ & $7.81 \pm 0.06$ \\
\hline & & Minch & $2.67 \pm 0.11$ & $1.13 \pm 0.04$ & $0.95 \pm 0.04$ & $8.62 \pm 0.05$ \\
\hline & & T. Wuha & $5.01 \pm 0.04$ & $4.16 \pm 0.04$ & $2.02 \pm 0.07$ & $11.59 \pm 0.06$ \\
\hline & \multirow{2}{*}{ Ziway } & Bochesa & $3.49 \pm 0.06$ & $2.89 \pm 0.06$ & $6.10 \pm 0.07$ & $13.33 \pm 0.06$ \\
\hline & & Shallo & $3.68 \pm 0.11$ & $5.09 \pm 0.06$ & $5.06 \pm 0.07$ & $15.33 \pm 0.08$ \\
\hline \multirow{5}{*}{ Scale } & \multirow{3}{*}{ Awassa } & Deset & $6.13 \pm 0.03$ & $3.50 \pm 0.07$ & $7.38 \pm 0.07$ & $6.04 \pm 0.05$ \\
\hline & & Minch & $4.46 \pm 0.04$ & $4.27 \pm 0.06$ & $5.33 \pm 0.07$ & $7.51 \pm 0.04$ \\
\hline & & T. Wuha & $12.13 \pm 0.06$ & $5.10 \pm 0.06$ & $8.69 \pm 0.06$ & $24.49 \pm 0.05$ \\
\hline & \multirow{2}{*}{ Ziway } & Bochesa & $13.24 \pm 0.05$ & $2.13 \pm 0.06$ & $8.43 \pm 0.09$ & $8.26 \pm 0.06$ \\
\hline & & Shallo & $9.22 \pm 0.06$ & $5.74 \pm 0.05$ & $10.96 \pm 0.08$ & $14.60 \pm 0.05$ \\
\hline \multirow{5}{*}{ Spleen } & \multirow{3}{*}{ Awassa } & Deset & $5.07 \pm 0.13$ & $1.10 \pm 0.55$ & $11.64 \pm 0.95$ & $7.42 \pm 0.41$ \\
\hline & & Minch & $6.66 \pm 0.21$ & $1.26 \pm 0.68$ & $12.68 \pm 0.53$ & $2.91 \pm 0.22$ \\
\hline & & T. Wuha & $3.58 \pm 0.30$ & $1.51 \pm 0.52$ & $12.76 \pm 0.64$ & $16.48 \pm 0.36$ \\
\hline & \multirow{2}{*}{ Ziway } & Bochesa & $3.55 \pm 0.54$ & $0.47 \pm 0.27$ & $10.53 \pm 0.64$ & $4.58 \pm 0.57$ \\
\hline & & Shallo & $2.58 \pm 0.25$ & $1.36 \pm 0.50$ & $13.20 \pm 0.74$ & $6.21 \pm 0.35$ \\
\hline \multirow{5}{*}{ Sediment } & \multirow{3}{*}{ Awassa } & Deset & $3.19 \pm 0.09$ & $4.14 \pm 0.41$ & $13.39 \pm 1.13$ & $26.91 \pm 0.76$ \\
\hline & & Minch & $8.43 \pm 0.07$ & $6.07 \pm 0.41$ & $18.24 \pm 0.85$ & $31.31 \pm 0.91$ \\
\hline & & T. Wuha & $9.18 \pm 0.09$ & $8.66 \pm 0.41$ & $37.72 \pm 1.34$ & $37.77 \pm 0.61$ \\
\hline & \multirow{2}{*}{ Ziway } & Bochesa & $8.75 \pm 0.07$ & $4.67 \pm 0.50$ & $9.42 \pm 0.70$ & $33.98 \pm 0.78$ \\
\hline & & Shallo & $10.51 \pm 0.13$ & $7.52 \pm 0.30$ & $31.11 \pm 1.51$ & $78.49 \pm 0.60$ \\
\hline \multirow{5}{*}{ Water } & \multirow{3}{*}{ Awassa } & Deset & $0.007 \pm 0.001$ & $0.05 \pm 0.004$ & $<0.05$ & $0.04 \pm 0.002$ \\
\hline & & Minch & $0.007 \pm 0.001$ & $0.05 \pm 0.002$ & $<0.05$ & $0.03 \pm 0.002$ \\
\hline & & T. Wuha & $<0.005$ & $0.09 \pm 0.004$ & $<0.05$ & $0.03 \pm 0.002$ \\
\hline & \multirow{2}{*}{ Ziway } & Bochesa & $0.01 \pm 0.001$ & $0.06 \pm 0.007$ & $<0.05$ & $0.03 \pm 0.006$ \\
\hline & & Shallo & $0.009 \pm 0.001$ & $0.06 \pm 0.002$ & $0.064 \pm 0.004$ & $0.04 \pm 0.002$ \\
\hline
\end{tabular}


Table 4: Trace element concentrations in organs of $O$. niloticus, sediment and water samples from Lakes Awassa and Ziway.

\begin{tabular}{|c|c|c|c|c|c|c|}
\hline \multirow[t]{2}{*}{ Type } & \multirow{2}{*}{$\begin{array}{l}\text { Name of } \\
\text { Lake }\end{array}$} & \multirow{2}{*}{$\begin{array}{l}\text { Sampling } \\
\text { Site }\end{array}$} & \multicolumn{4}{|c|}{ Concentration of $(\mathrm{mg}$ element/kg)* dry weight } \\
\hline & & & Lead & Manganese & Nickel & Zinc \\
\hline \multirow{5}{*}{ Bile } & \multirow{3}{*}{ Awassa } & Deset & $8.50 \pm 0.17$ & $0.82 \pm 0.06$ & $5.59 \pm 0.25$ & $22.42 \pm 0.05$ \\
\hline & & Minch & $5.73 \pm 0.19$ & $1.02 \pm 0.04$ & $5.25 \pm 0.58$ & $31.99 \pm 0.03$ \\
\hline & & T. Wuha & $14.86 \pm 0.12$ & $5.78 \pm 0.03$ & $5.81 \pm 0.29$ & $55.79 \pm 0.09$ \\
\hline & \multirow{2}{*}{ Ziway } & Bochesa & $6.59 \pm 0.08$ & $0.97 \pm 0.08$ & $4.17 \pm 0.21$ & $18.42 \pm 0.07$ \\
\hline & & Shallo & $8.51 \pm 0.11$ & $1.03 \pm 0.04$ & $4.40 \pm 0.28$ & $45.05 \pm 0.11$ \\
\hline \multirow{5}{*}{ Intestine } & \multirow{3}{*}{ Awassa } & Deset & $6.24 \pm 0.56$ & $6.87 \pm 0.04$ & $3.04 \pm 0.03$ & $22.48 \pm 0.05$ \\
\hline & & Minch & $7.23 \pm 0.42$ & $41.10 \pm 0.07$ & $4.00 \pm 0.03$ & $27.38 \pm 3.02$ \\
\hline & & T. Wuha & $11.97 \pm 0.66$ & $53.38 \pm 0.03$ & $4.03 \pm 0.03$ & $27.60 \pm 0.03$ \\
\hline & \multirow{2}{*}{ Ziway } & Bochesa & $8.31 \pm 0.90$ & $27.12 \pm 0.04$ & $6.69 \pm 0.04$ & $30.58 \pm 0.04$ \\
\hline & & Shallo & $12.12 \pm 0.67$ & $58.94 \pm 0.09$ & $6.52 \pm 0.03$ & $32.48 \pm 0.05$ \\
\hline \multirow{5}{*}{ Scale } & \multirow{3}{*}{ Awassa } & Deset & $48.78 \pm 0.24$ & $135.1 \pm 0.13$ & $43.13 \pm 0.28$ & $68.68 \pm 0.14$ \\
\hline & & Minch & $37.29 \pm 0.12$ & $121.0 \pm 0.01$ & $42.33 \pm 0.18$ & $69.34 \pm 0.17$ \\
\hline & & T. Wuha & $56.03 \pm 0.13$ & $134.2 \pm 0.09$ & $44.43 \pm 0.16$ & $91.27 \pm 0.16$ \\
\hline & \multirow{2}{*}{ Ziway } & Bochesa & $40.93 \pm 0.21$ & $37.23 \pm 0.12$ & $45.98 \pm 0.18$ & $72.33 \pm 0.17$ \\
\hline & & Shallo & $49.03 \pm 1.68$ & $36.14 \pm 0.04$ & $46.61 \pm 0.23$ & $81.43 \pm 0.89$ \\
\hline \multirow{5}{*}{ Spleen } & \multirow{3}{*}{ Awassa } & Deset & $3.88 \pm 0.36$ & $0.86 \pm 0.51$ & $0.77 \pm 0.31$ & $4.81 \pm 0.37$ \\
\hline & & Minch & $3.35 \pm 0.12$ & $1.12 \pm 0.39$ & $2.60 \pm 1.14$ & $26.51 \pm 0.86$ \\
\hline & & T. Wuha & $2.32 \pm 0.86$ & $2.84 \pm 0.59$ & $2.78 \pm 0.90$ & $38.78 \pm 0.68$ \\
\hline & \multirow{2}{*}{ Ziway } & Bochesa & $1.46 \pm 0.46$ & $0.54 \pm 0.83$ & $2.40 \pm 0.36$ & $2.11 \pm 0.61$ \\
\hline & & Shallo & $1.78 \pm 1.82$ & $1.85 \pm 0.66$ & $0.98 \pm 0.86$ & $29.51 \pm 0.58$ \\
\hline \multirow{5}{*}{ Sediment } & \multirow{3}{*}{ Awassa } & Deset & $8.49 \pm 0.89$ & $136.40 \pm 2.15$ & $8.09 \pm 0.83$ & $107.48 \pm 0.33$ \\
\hline & & Minch & $9.97 \pm 0.62$ & $105.88 \pm 1.12$ & $11.85 \pm 1.06$ & $107.88 \pm 0.43$ \\
\hline & & T. Wuha & $20.18 \pm 0.83$ & $197.58 \pm 0.33$ & $20.16 \pm 1.07$ & $130.82 \pm 0.24$ \\
\hline & \multirow{2}{*}{ Ziway } & Bochesa & $8.55 \pm 0.56$ & $117.38 \pm 0.90$ & $15.17 \pm 0.62$ & $111.12 \pm 0.62$ \\
\hline & & Shallo & $20.18 \pm 0.83$ & $170.79 \pm 1.11$ & $24.00 \pm 1.05$ & $173.82 \pm 0.39$ \\
\hline \multirow{5}{*}{ Water } & \multirow{3}{*}{ Awassa } & Deset & $0.10 \pm 0.007$ & $<0.01$ & $<0.04$ & $0.46 \pm 0.002$ \\
\hline & & Minch & $<0.10$ & $0.02 \pm 0.024$ & $<0.04$ & $0.47 \pm 0.003$ \\
\hline & & T. Wuha & $0.18 \pm 0.01$ & $0.01 \pm 0.003$ & $0.07 \pm 0.006$ & $0.49 \pm 0.002$ \\
\hline & \multirow{2}{*}{ Ziway } & Bochesa & $0.11 \pm 0.013$ & $0.01 \pm 0.001$ & $<0.04$ & $0.46 \pm 0.003$ \\
\hline & & Shallo & $0.11 \pm 0.006$ & $0.01 \pm 0.001$ & $<0.04$ & $0.47 \pm 0.001$ \\
\hline
\end{tabular}



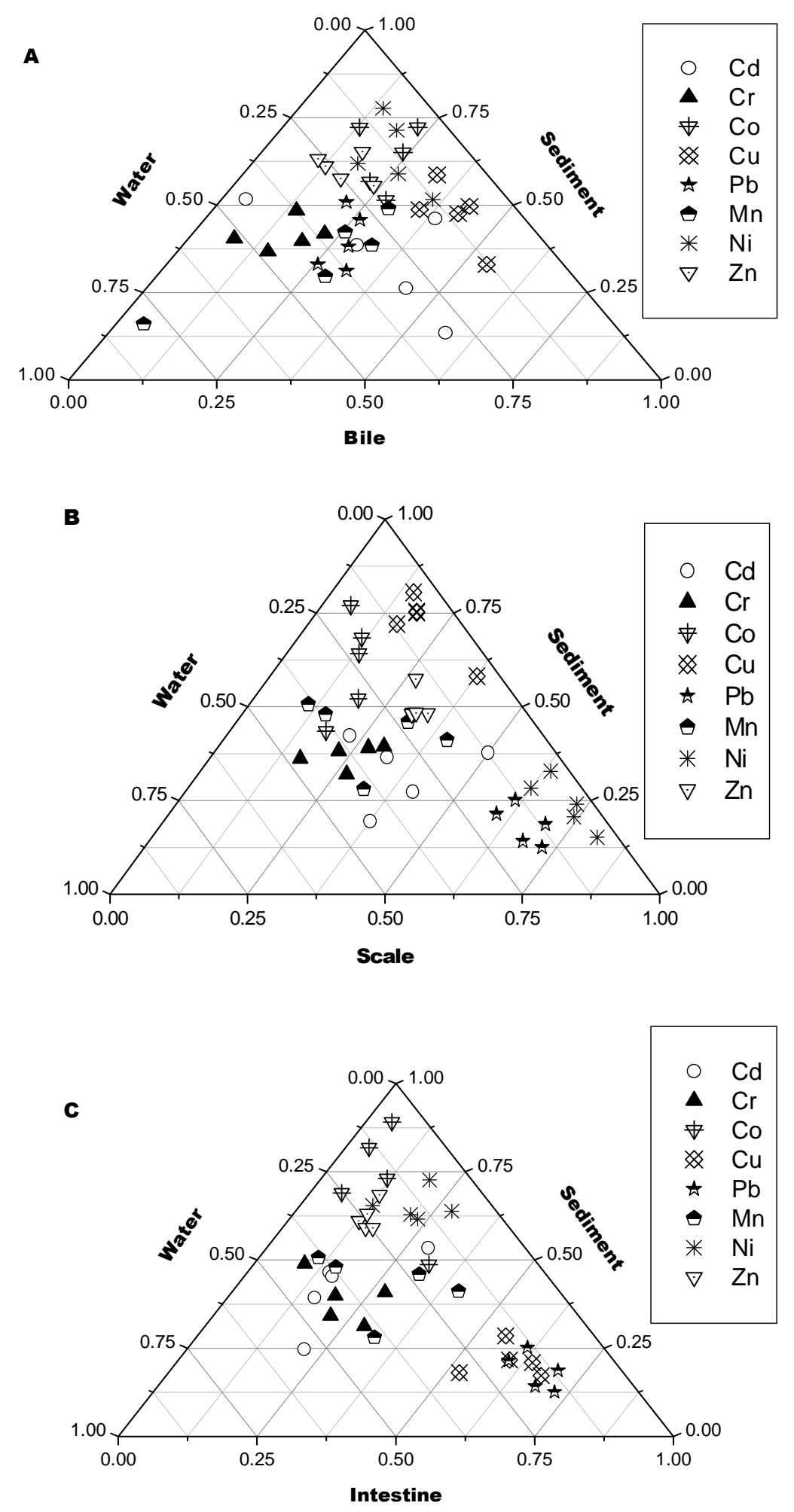


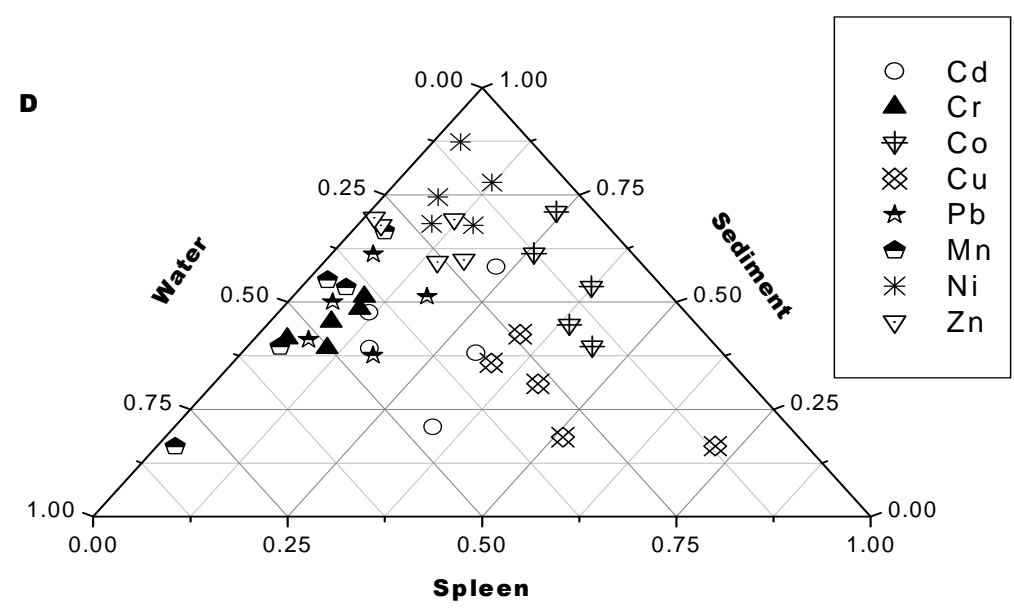

Figure 1: Ternary plot that shows the correlation between organs of fish, sediment and water: A) bile - sediment - water; B) scale - sediment - water; C) intestine - sediment - water; D) spleen-sediment - water.

\section{DISCUSSION}

Selection of organs for analysis

First of all an understanding of the mechanisms or modes of action for the chemical of concern is important such that the appropriate organs are selected and sampled. Selection of the appropriate organs can be specific to contaminants. For example, the appropriate organ for lead and cadmium may be different from that of copper and zinc (Zhou et al., 1998). The majority of studies linking organ level with effects reported that lead would accumulate in organs which contain high amounts of calcium (e.g. scale) and spleen (Yoshitomi et al., 1998). Since bile is continually renewed with its content, analyzing its trace metal constituent gives evidence for immediate contamination. The intestine is the main organ for food digestion and storage while spleen is attached to it. The spleen acts as an organ of detoxification of metal contaminants since it produces metallothionein. The scale is outermost organ of the fish and continuously comes in contact with water and the pollutants therein, which makes it a very good bioindicator of the state of pollution (Rishi and Jaik, 1998; Yoshitomi et al., 1998).

\section{Dry mass determination}

Concentrations of metals in fish are widely reported both on dry mass and wet mass basis (Kress et al., 1998; Al-Yousef et al., 2000; Cohen et al., 2001). However, dry mass permits more accurate assessment of metal load since water content in biota varies with species, age, and condition (Kress et al., 1998). The water content of the selected organs of the fish, $O$. niloticus (scale, spleen and intestine) was determined by measuring the mass loss of the organs using freeze drying unit until constant mass was obtained. The moisture content was calculated as percentage loss of the body part of the fish. The moisture content determined for intestine and spleen in this study is in good agreement with previous reports from our laboratory (Ataro et al., 2003; Kebede and Wondimu, 2004). It was also comparable with the results of Zauke et al. (1999), which was $82 \%$ for different fish species. The range for percentage moisture content was $78.12 \%$ to $83.46 \%$ for intestine, $38.81 \%$ to $52.07 \%$ for scale, and $75.06 \%$ to $80.86 \%$ for spleen. High water content of intestine was observed because it contains biological fluids and is a storage organ of food. But, scale revealed low water content as it is the external fish organ. 


\section{Optimization of digestion methods}

Trace metal determinations in fish and sediment commonly involve some types of mineral acid extraction before analysis with flame atomic absorption spectrometer. Such methods are reasonably less inexpensive, and provide satisfactory precision and reproducibility for environmental monitoring purposes. However, to reduce interference by organic matter and convert metals associated with particulates to a form that can be determined by atomic absorption spectrometry, digestion with acids is the preferred technique. Literature reports recommend different combination of mineral acids with/without hydrogen peroxide for the decomposition of fish organs and sediments (Al-Yousef et al., 2000; Cohen et al., 2001; Gebremariam and Desta, 2002; Papagiannis et al., 2004; Begum et al., 2009). Various digestion procedures were tested to digest bile, intestine, scale, spleen and sediment samples. Refluxing has the advantage of decreasing blank values due to reduced reagent volumes and contamination from the working environment.

\section{Organ specific distribution pattern}

The distribution and accumulation of metals in fish organs depends on the metal type, interaction with natural factors, ability to bind metals in forms that are not biologically available, character of mechanisms determining bioaccumulation and excretion of metals, and also on the type of tissue, fish species, size and age (Al-Yousef et al., 2000). The metals cadmium, chromium, cobalt, copper, lead, manganese, nickel and zinc are of particular interest because: (1) when in excess or deficient, they are toxic to the aquatic organisms and persistent in the aquatic environment; (2) they have anthropogenic sources that are likely to cause elevated levels in the aquatic environment; (3) there are information available to discuss specific organ accumulation of metals; and (4) biota concentrations for these metals have been reported for naturally occurring aquatic organisms.
In the bile the concentrations of the trace metals was lowest for cobalt and highest for zinc. The trend was $\mathrm{Zn}>\mathrm{Cu}>\mathrm{Pb}>\mathrm{Cd}>$ $\mathrm{Ni}>\mathrm{Cr}>\mathrm{Mn}>\mathrm{Co}$. The bile samples produced a clear grouping of the results, which is in accordance with Westwelund (1998). The metals are excreted into the bile in fish, which represents a physiological loop, within which most of the metals are reabsorbed in the intestine. Based on the difference in physiological turnovers of the metals in the fish and nutritional or water quality differences between the locations, there could be variation in excretion and metal concentration. Together with metals in the other organs, it does offer additional information on the concentration of the elements. Even if identifying and sample collection of bile seems difficult, its elemental analysis offers a quick way of screening the metals. High concentration of zinc is seen in the results, which is similar to Westerlund (1998).

In the intestine, manganese had the highest concentration while cobalt had the lowest concentration. The general trend is $\mathrm{Mn}$ $>\mathrm{Zn}>\mathrm{Cu}>\mathrm{Pb}>\mathrm{Ni}>\mathrm{Cd}>\mathrm{Cr}>\mathrm{Co}$. A high accumulation of manganese, zinc, copper and lead is seen in the intestine as observed by (Zhou et al., 1998). The relatively high content of these metals found in the intestine could be due to the fact that most of the heavy metals are accumulated in the liver and kidney after ingestion, or excessive metals in the diets are not absorbed but remain in the intestine. On the other hand, fish have different routes of possible excretion of heavy metals when exposed to trace metal contaminated water bodies that include, intestine (via feces), scale and kidney. All these factors may contribute to levels of trace metals in the intestine. The high accumulation of the metals might be related to specific mechanisms for Tilapia. Perhaps an efficient accumulation and excretion route via the intestine contributes to the tolerance of Tilapia to the high levels of these metals (Zhou et al., 1998). It should be emphasized that it is difficult to figure out exactly what the fish consumed because some 
fish species change their feeding materials during growth (Liang et al., 1999). Liang et al. (1999) reported to display high concentrations of zinc and copper (manganese not included) in Tilapia, which is in agreement with the results of present study.

Highest concentration of manganese and lowest concentration of chromium was observed in the scale. The accumulation pattern was as $\mathrm{Mn}>\mathrm{Zn}>\mathrm{Pb}>\mathrm{Ni}>\mathrm{Cu}>\mathrm{Cd}$ $>\mathrm{Co}>\mathrm{Cr}$. The high accumulation of zinc and manganese in scale could be attributed to high levels of these metals in the underlying sediment and the aquatic system. In the case of lead and nickel, the reason for their accumulation could be that the scale acts as the body part for calcification, so lead will mimic with the calcium of the body and accumulate more in the scale by replacing the body calcium. Besides lead and nickel, scale also accumulates certain metals like selenium and arsenic to a greater extent than the muscle (Farrell et al., 2000). So it should be stressed that scale concentrations could overestimate, but rarely underestimate muscle concentrations. It is, therefore, advisable to use scale metal concentration analysis with other organs.

In the case of spleen, the highest concentration was observed for zinc, while the lowest for chromium. The trend for the metal distribution in spleen is $\mathrm{Zn}>\mathrm{Co}>\mathrm{Cu}>\mathrm{Cd}>$ $\mathrm{Pb}>\mathrm{Ni}>\mathrm{Mn}>\mathrm{Cr}$. The high accumulation of zinc could be linked to natural origin, i.e., the underlying base rocks, nearby hot springs, and soil erosion. It is difficult to say why low levels of manganese were seen in the spleen, which needs further investigation. The spleen, liver and kidney are important organs for trace metal storage and decontamination in fish, where metallothionein induced by trace metals takes place (Liang et al., 1999). The size of the spleen is very small which might affect the concentration of the metals. Thus, it may be reasonable to expect low levels of metals in spleen compared to the other organs.

Among the organs, the scale accumulated large amount of cadmium while the lowest was for the intestine. The distribution pattern is scale $>$ bile $>$ spleen $>$ intestine. The concentration of chromium in the organs was highest for scale while the lowest was for spleen. The spleen was found to be accumulating large amounts of cobalt while the lowest for bile. In general its accumulation was observed as spleen $>$ scale $>$ intestine > bile. Therefore the scale can accumulate cadmium and chromium while spleen accumulates cobalt. The reason could be the scale is one of the parts for calcification so that cadmium will replace the calcium in the body particularly in the scale, gill, bone opercula, etc. The spleen has a few numbers of metallothionein, which binds metal and detoxify them. In the organs, the highest concentration of copper was observed in the scale and lowest in the spleen. The distribution pattern is that scale > intestine > bile > spleen. Since there is no much difference between copper levels in the organs, we cannot say copper accumulates preferentially in one part. Its internal concentration in the fish will be regulated and fixed at a certain concentration. In the organs, lead is highly accumulated in the scale while lowest in the spleen. The trend is scale > intestine $>$ bile $>$ spleen. As in the case of cadmium since lead resembles calcium and mimics the cells, the part for calcification, scale, accumulate lead. In the case of nickel, the scale and spleen have the highest and lowest concentrations, respectively. The trend is scale > intestine > bile > spleen. It can be inferred that nickel would accumulate in the scale than the other organs. The highest concentrations of manganese and zinc were observed in most of the organs. High concentration of manganese and zinc were observed in the scale while the lowest for spleen. The trend looks like scale > intestine > bile > spleen. To see the correlations among the four organs for the analyzed metals, Pearson's Correlation Matrix was applied using Microsoft Excel 2007 Software. In most of the cases, the results showed that for chromium, cobalt, copper, lead (except with spleen that showed strong negative association), manganese, nickel and zinc have 
strong positive association (having a value of Pearson's correlation coefficient, $r$ between +0.7 and +1.0), however for the case of cadmium mostly weak negative association (having a value of $r$ between -0.7 and -0.3 ).

\section{Distribution pattern of metals in sediment and water samples}

Trace metals are introduced into the aquatic environment through various routes. They generally gain access into the aquatic systems, through atmospheric fallout, dumping wastes, accidental leaks, runoff of industrial and domestic effluents and geological origins (Al-Yousef et al., 2000). Sediments have been reported to form the major repository of heavy metal in the aquatic system while both allochthonous and autochthonous influences could make a concentration of heavy metals in the water high enough to be ecological significance. Bioaccumulation and magnification is capable of leading to toxic level of heavy metals in the fish, even when exposure is low. The presence of metal pollutant in fresh water is known to disturb the delicate balance of the aquatic ecosystem. The distribution of heavy metals in water bodies reveal that the levels of heavy metals in the bottom sediment are usually higher than the water columns which shows that sediments act as sink of heavy metals (Olowu et al., 2010). The highest concentration of manganese and the lowest concentration of chromium were observed in the sediment. The general distribution of the metals looks like $\mathrm{Mn}>\mathrm{Zn}>\mathrm{Cu}>\mathrm{Co}>\mathrm{Ni}>$ $\mathrm{Pb}>\mathrm{Cd}>\mathrm{Cr}$. The high concentrations of manganese, zinc and copper could be of natural origin. These metals easily form complexes with organic compounds because of the high formation constants of organicmetal compounds, which make them rather stable in the environment (Zhou et al., 1998). In the case of zinc, it can associate with carbonate, mainly calcium carbonate, by forming the double salt of $\mathrm{CaCO}_{3} \cdot \mathrm{ZnCO}_{3}$ in the sediment. On the other hand, cadmium and chromium are not found in organic fraction for low adsorption constant and liable complexion with organic matter (Zhou et al., 1998). The pattern for the metals in the water samples varied as $\mathrm{Zn}>\mathrm{Pb}>\mathrm{Cr}>\mathrm{Co}>\mathrm{Cu}>$ $\mathrm{Ni}>\mathrm{Mn}>\mathrm{Cd}$. The observed low concentrations of the metals in water could be attributed to dilution effects. Dilution masks the local concentration effects of the low and chronic exposure of the metals, by quickly reducing the concentration levels in the water.

\section{Correlation of concentrations of trace metals in fish, sediment and water}

Literature reports reveal that trace metals tend to accumulate and biomagnify in organs of living organisms (Kress et al., 1998). In order to see such behavior, attempt was made to correlate the concentrations of trace metals in organs of fish with that in the lake sediment and the lake water (Widianarko et al., 2000; Chale, 2002). To see the correlations of concentrations of trace metals in fish organ, with those in sediment and water, a ternary plot was used (Figure 1: A, B, $\mathrm{C}$ and D) using Microcal Origin 8.0 software, to identify trends and relationships between groups of samples. In ternary plot, the triangular coordinate systems are used to plot four variables (the component organs of fish, sediment, and water, and the response, i.e., element) in two dimensions (ternary scatter plots). The samples (fish, water and sediment) analyzed were collected from five sampling sites (three different sites in Lake Awassa and two different sites in Lake Ziway) and were analyzed for the contents of eight metals in the specific organ of the fish. Thus there are 40 points in a single ternary plot (eight metals from five sites) and they are correlated with the three variables in the three axes (particular fish organ, water and sediment). As can be seen from the plot, there is a positive correlation between the fish organs with that of sediment and water. In the case of bile and spleen there is a positive correlation between every element in the organ with that of the sediment and water, however in the cases of intestine copper and scale nickel correlation is not good as compared to the other elements. When correlation of elements with sediment 
or water is assessed, the elements show strong positive correlation with that of sediment than that of water which shows that the main source could be the sediment where high concentration of the elements in general observed. For most of the elements good correlation was evident; but notable correlation was observed particularly for chromium, manganese, nickel, zinc, cobalt and lead. In the case of copper and cadmium, correlation was poor in most of the cases since the correlation points are so dispersed. Low correlations could be ascribed to one or more of the following factors: (1) Fish regulate most elements using various homeostatic control mechanisms; hence, even though in some cases the fish in proportion to their broad concentration range in the sediment takes up these elements, they may not accumulate in the body. (2) Many factors control the bioavailability of metals to organisms making determination of the form available for uptake difficult and correlations between organs and sediment equivocal. Because sediments vary widely in the grain size, organic (humic and fulvic acids) and inorganic (sulfides) ligands, redox state, cation exchange capacity, $\mathrm{pH}$, etc., and our understanding of their function is incomplete, it is not possible at this time to determine the portion of the total trace metal concentrations in sediment that is available for uptake. (3) Elements in sediment are commonly distributed in a nonhomogenous fashion over small geographic areas, whereas fish are mobile over large distances in the water; hence accumulation of elements by fish within a site may be so variable that correlation analysis would be futile. (4) Metal accumulation pattern also depends on the fish species, age, and weather condition. Due to the above factors getting a high correlation can be difficult.

In the whole analysis the accumulation trend of cadmium is scale > bile > sediment $>$ spleen > intestine > water. The highest concentration of chromium was found in the sediment and the lowest for water. The reason for the high accumulation of chromium in sediment could be: it is strongly attached to the bed sediment by forming chromium hydroxide. For the whole analysis the distribution of cobalt is sediment $>$ spleen $>$ scales $>$ intestine $>$ bile $>$ water while for copper is sediment $>$ scale $>$ intestine $>$ bile $>$ spleen $>$ water. The highest concentration of lead was observed for the scale while it was lowest for water. The pattern is scale > sediment $>$ intestine $>$ bile $>$ spleen $>$ water, while for the case of nickel the trend is scale $>$ sediment $>$ intestine $>$ bile $>$ spleen $>$ water. It can be inferred that nickel would accumulate in the scale than the other organs. Sediment and water has the highest and lowest concentrations of the both zinc and manganese, respectively, where the pattern is sediment $>$ scale $>$ intestine $>$ bile $>$ spleen $>$ water.

Due to the dilution factor, water has the lowest concentration of all the metals, even in some cases the concentrations were below the detection limit of the instrument and the method itself. The trace elements generally showed accumulation in specific organs of the fish. Moreover, the physiological role of the element, the preference of the element to bind or replace some element(s) in the organ could be the factors governing the specific organ accumulation patterns of the metals. Generally the trend for the total concentrations of the selected elements in the analysis is sediment > scale $>$ intestine $>$ bile $>$ spleen $>$ water. It is obvious to see high concentration for trace metals in the sediment because of the reason that the sources of the metals could be geological in origin or from the sediment.

This work represents the first attempt to establish correlation of trace metals in organs of fish with that in the sediment and water and assess the extent of contamination of the lake water by trace metals. Although human impact on the catchments is not absent, the sources of trace metals seem to be mainly geological in origin, as determined by sediment analysis. The continuous input from thermal springs into Lakes Awassa and Ziway appears contributory factor to the accumulation of trace metals in the fish. 
Comparing the two lakes, Lake Awassa seemed to show high concentrations of trace metals than Lake Ziway. This may indicate exposure of the lake to effluents from factories and domestic sewages in addition to absence of refreshing rivers. Besides, the town of Awassa is growing faster, which may imply greater degree of anthropogenic effects on Lake Awassa. This may account for the slightly elevated levels of metals in Lake Awassa. Currently, both Awassa and Ziway are fast growing towns with growing settlements and accompanied discharges seen very near to the lakes. If this trend continues, the amount of pollutants discharged from the residents will increase and contaminate the lakes. Therefore, a single unified contaminant monitoring, an aggressive bioassessment initiative is needed to determine the viability of fish population in the water and conservation of the aquatic system. While the aquatic systems considered in this study belong to a supposedly pristine environment, high concentrations of certain toxic elements (such as lead and cadmium) were determined. Since the anthropogenic contributions in the region are low compared with developed nations, the underlying base rocks, nearby hot springs, and soil erosion could have contributed by large to the levels of these metals in the lakes. Perhaps aforestation of the catchments could minimize siltation problem and reduce the inflow of metals in the lakes.

\section{ACKNOWLEDGMENTS}

Financial assistance by the Swedish International Development Agency (SIDA) through the Ethiopian Science and Technology Commission and the Office of Research and Graduate Programs and Department of Chemistry of Addis Ababa University, Ethiopia is gratefully acknowledged. Kebede Nigussie acknowledges financial support made by Mekelle University.

\section{REFERENCES}

Alemu K. 2003. The growth performance of $O$. niloticus $L$. related in fresh water ponds loaded with varying levels of poultry manure. SINET: Ethiop. J. Sci., 26: 17-23.

Al-Yousef MH, El-Shahawi MS, Al-Ghais SM. 2000. Trace metals in liver, skin and muscle of Lethrinus lentjan fish species in relation to body length and sex. Sci. Total Environ., 256: 87-94.

Ataro A, Wondimu T, Chandravanshi BS. 2003. Determination of trace metals in selected fish species from Lakes Awassa and Ziway. SINET: Ethiop. J. Sci., 26: 103-114.

Begum A, Krishna HS, Khan I. 2009. Analysis of heavy metals in water, sediments and fish samples of Madivala Lakes of Bangalore, Karnataka. Int. J. Chem. Tech. Res., 1(2): 245-249.

Breuil C. 1995. FAO Fisheries Circular No 890, FAO-UN: Rome; 1-29.

Chale FMM. 2002. Trace metal concentrations in water, sediments and fish tissue from Lake Tanganyika. Sci. Total Environ., 299: 115-121.

Cohen T, Que Hee SS, Ambrose RF. 2001. Trace metals in fish and invertebrates of three California coastal wetlands. Mar. Pollut. Bull., 42: 224-232.

Farrell AP, Hodlay AH, Wang S. 2000. Metal analysis of scales taken from Arctic grayling. Arch. Environ. Contam. Toxicol., 39: 515-522.

Gebremariam Z, Desta Z. 2002. The chemical composition of the effluent from Awassa Textile Factory and its effects on aquatic biota. SINET: Ethiop. J. Sci., 25: 263274.

Getahun A, Stiassny MLJ. 1998. The Freshwater biodiversity crisis: the case of the Ethiopian fish fauna. SINET: Ethiop. J. Sci., 21: 207-230.

Kebede A, Wondimu T. 2004. Distribution of trace elements in muscle and organs of Tilapia, Oreochromis niloticus from Lakes Awassa and Ziway. Bull. Chem. Soc. Ethiop., 18, 119-130.

Kress N, Hornung H, Herut B. 1998. Concentrations of $\mathrm{Hg}, \mathrm{Cd}, \mathrm{Cu}, \mathrm{Zn}, \mathrm{Fe}$ and $\mathrm{Mn}$ in deep sea benthic fauna from the 
Southeastern Mediterranean Sea: a comparison study between fauna collected at a pristine area. Mar. Pollut. Bull., 36: 911-921.

Liang L, Cheung RYH, Wong MH. 1999. Reclamation of wastewater for polyculture of freshwater fish: bioaccumulation of trace metals in fish. Wat. Res., 33: 2690-2770.

Mwashote BM. 2003. Levels of cadmium and lead in water, sediments and selected fish species in Mombasa, Kenya. Western Indian Ocean J. Mar. Sci., 2: 25-34.

Olowu RA, Ayejuyo OO, Adewuyi GO, Adejoro IA, Denloye AAB, Babatunde AO, Ogundajo AL. 2010. Determination of heavy metals in fish tissues, water and sediment from Epe and Badagry Lagoons, Lagos, Nigeria. E-J. Chem., 7(1): 215221.

Öztürk M, Özözen G, Minareci O, Minareci E. 2009. Determination of Heavy metals in fish, water and sediments of Avsar Dam Lake in Turkey. Iran. J. Environ. Health. Sci. Eng., 6(2): 73-80.

Papagiannis I, Kagalou I, Leonardos J, Petridis D, Kalfakakou V. 2004. Copper and zinc in four freshwater fish species from Lake Pamvotis (Greece). Environ. Int., 30: 357-362.

Pourang N, Nikouyan A, Dennis JH. 2005. Trace element concentrations in fish, surficial sediments and water from Northern part of the Persian Gulf. Environ. Monit. Assess., 109: 293-316.

Rashed MN. 2001. Monitoring of environmental heavy metals in fish from Nasser Lake. Environ. Int., 27: 27-33.
Rishi KK, Jaik, M. 1998. Effect of toxicity of cadmium on scale morphology in Cyprinus carpio (Cyprinidae). Bull. Environ. Contam. Toxicol., 60: 323-328.

Turkmen M, Ciminli C. 2007. Determination of metals in fish and mussel species by inductively coupled plasma-atomic emission spectrometry. Food Chem., 103: 670-675.

Westerlund S, Aas E, Andersen OK. 1998. The use of bile in fish in screening methods for trace metal exposure. Mar. Environ. Res., 46: 601-604.

Widianarko A, Gestel CAM, Verweij RA, Straalen VNM. 2000. Association between trace metals in sediment, water, and Guppy, Poecilia reticulata (Peters), from urban streams of Semarang, Indonesia. Ecotoxicol. Environ. Safety, 46: 101-107.

Yilmaz AB, Sangun MK, Yaglioglu D, Turan. C. 2010. Metals (major, essential to nonessential) composition of the different tissues of three demersal fish species from Iskenderun Bay, Turkey. Food Chem., 123: 410-415.

Yoshitomi T, Koyama J, Iida A, Okamoto N, Ikeda Y. 1998. Cadmium-induced scale deformation in carp (Cyprinus carpio). Bull. Environ. Contam. Toxicol., 60: 639644.

Zauke GP, Savironv VM, Rifferhoff J, Savinova T. 1999. Heavy metals in fish from the Barents Sea (summer 1994). Sci. Total Environ., 227: 161-173.

Zhou HY, Cheung RYH, Chan KM, Wong MH. 1998. Metal concentrations in sediments and Tilapia collected from inland waters of Hong Kong. Wat. Res., 32: 3331-3340. 